This item was submitted to Loughborough's Research Repository by the author.

Items in Figshare are protected by copyright, with all rights reserved, unless otherwise indicated.

\title{
Uncertainty in through-life costing-review and perspectives
}

PLEASE CITE THE PUBLISHED VERSION

http://dx.doi.org/10.1109/TEM.2010.2040745

PUBLISHER

(c) IEEE

VERSION

VoR (Version of Record)

LICENCE

CC BY-NC-ND 4.0

REPOSITORY RECORD

Goh, Yee M., Linda B. Newnes, Antony R. Mileham, Chris McMahon, and Mohammad E. Saravi. 2019.

"Uncertainty in Through-life Costing-review and Perspectives". figshare. https://hdl.handle.net/2134/8079. 
This item was submitted to Loughborough's Institutional Repository (https://dspace.lboro.ac.uk/) by the author and is made available under the following Creative Commons Licence conditions.

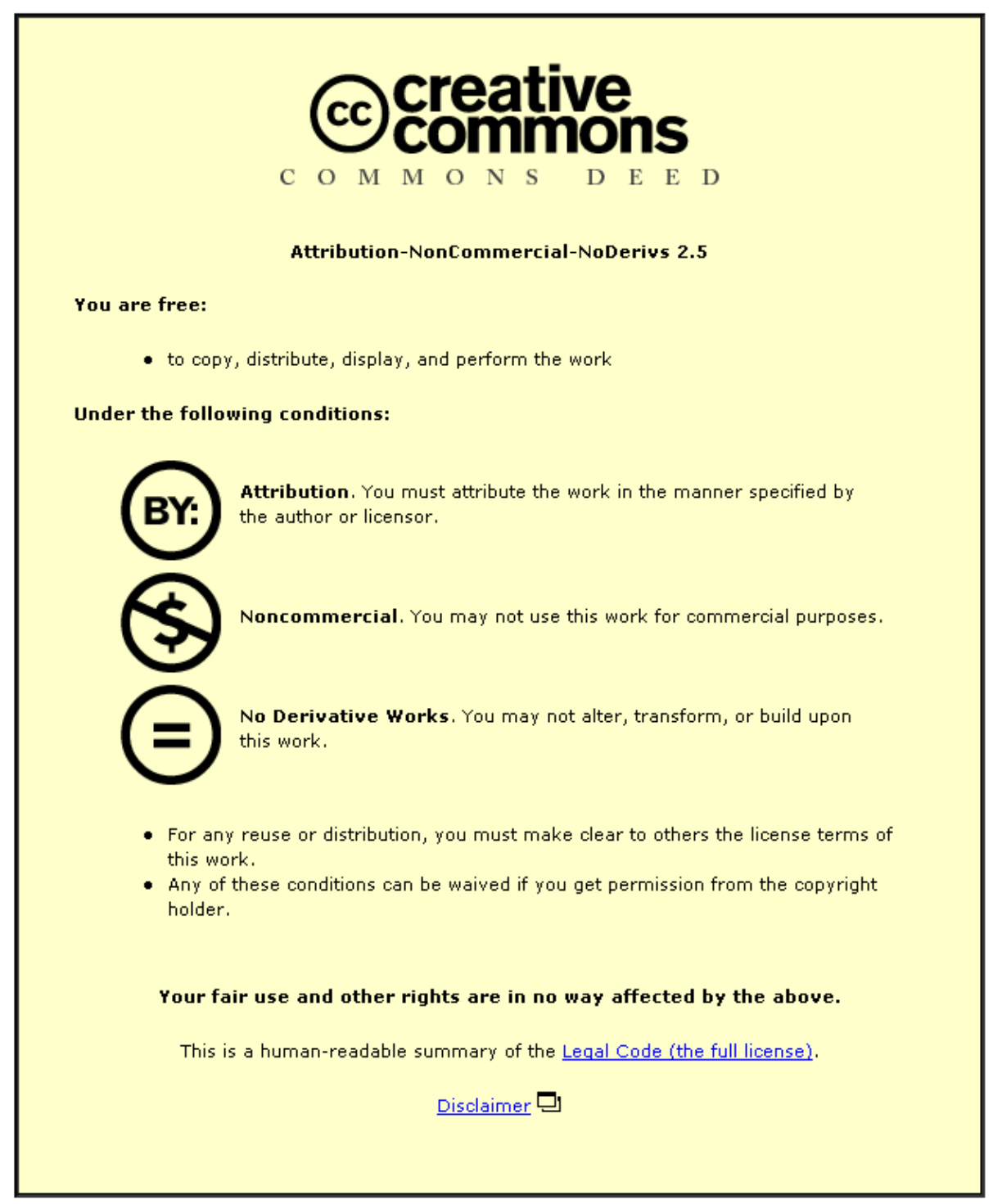

For the full text of this licence, please go to: http://creativecommons.org/licenses/by-nc-nd/2.5/ 


\title{
Uncertainty in Through-Life Costing-Review and Perspectives
}

\author{
Yee Mey Goh, Linda B. Newnes, Antony R. Mileham, Chris A. McMahon, and Mohammad E. Saravi
}

\begin{abstract}
Estimating through-life cost (TLC) is an area that is critical to many industrial sectors, and in particular, within the defense and aerospace where products are complex and have extended life cycles. One of the key problems in modeling the cost of these products is the limited life-cycle information at the early stage. This leads to epistemic and aleatory uncertainty within the estimation process in terms of data, estimation techniques, and scenarios analysis. This paper presents a review of the uncertainty classification in engineering literature and the nature of uncertainty in TLC estimation. Based on the review, the paper then presents a critique of the current uncertainty modeling approaches in cost estimation and concludes with suggestion for the requirement of a different approach to handling uncertainty in TLC. The potential value of imprecise probability should be explored within the domain of TLC to assist cost estimators and decision makers in understanding and assessing the uncertainty. The implication of such a representation in terms of decision making under risk and decision making under uncertainty is also discussed.
\end{abstract}

Index Terms-Cost estimation, decisions under risks and uncertainty, through-life cost (TLC), uncertainty.

\section{INTRODUCTION}

$\mathbf{T}$ HROUGH-LIFE cost (TLC) is a term used in cost estimation of a product from an early conceptual phase in the product life cycle through to the reuse/disposal phase. There are many acronyms that are used to mean TLC, such as whole-life costing (WLC), life-cycle costing (LCC), total cost, total life costing, total cost of ownership, cradle-to-grave costs, costs in use, and ultimate life cost [1]. This variation in terminology arises due to slight differences in definition and emphasis of the approach by different researchers, for instance, LCC is defined as "a set of methods that consider not only product life cycle costs but also the environmental and social aspects in the life cycle" [2]. This definition emphasizes environmental and social costs because much of the incentives come from the need for

Manuscript received May 18, 2009; revised August 29, 2009 and November 14, 2009; accepted December 12, 2009. Date of publication March 18, 2010; date of current version October 20, 2010. This work was supported by the Innovative Design and Manufacturing Research Centre, University of Bath, U.K., funded by the Engineering and Physical Science Research Council, under Grant GR/R67507/01. Review of this manuscript was arranged by Department Editor J. Sarkis.

Y. M. Goh, L. B. Newnes, C. A. McMahon, and M. E. Saravi are with the Department of Mechanical Engineering, Innovative Design and Manufacturing Research Centre, University of Bath, Bath, BA2 7AY, U.K. (e-mail: y.m.goh@bath.ac.uk; 1.b.newnes@bath.ac.uk; c.a.mcmahon@bath. ac.uk; m.ebrahimzadeh.saravi@bath.ac.uk).

A. R. Mileham is with the Department of Mechanical Engineering, Innovative Design and Manufacturing Research Centre, University of Bath, Bath, BA2 7AY, U.K., and also with the University of Canterbury, Christchurch 8140, New Zealand (e-mail: a.r.mileham@bath.ac.uk).

Color versions of one or more of the figures in this paper are available online at http://ieeexplore.ieee.org.

Digital Object Identifier 10.1109/TEM.2010.2040745 environmentally sustainable designs, bridging the link to life cycle analysis (LCA) [3]. According to the American Institute of Chemical Engineers (AIChE) total cost assessment methodology [4], five categories of costs are distinguished, with the trend of each category being increasingly more difficult to quantify:

Type 1: direct (capital investment, recurring and nonrecurring);

Type 2: indirect (operating and maintenance, recurring and nonrecurring);

Type 3: contingent (future scenarios, accidental);

Type 4: Intangible (customer loyalty, worker morale);

Type 5: External costs (societal costs).

The emphasis in this paper is on the tangible costs (types 1-3) in the AIChE classification.

Defense acquisition strategies such as the U.S. Department of Defense (DoD) performance-based logistics (PBL) and the U.K. Ministry of Defence (MoD) through life capability management are contracting the original equipment manufacturers (OEMs) to provide long-term support, taking into account the financial implications of equipment through life [5], [6]. For large engineering systems with extended life, costs of operating and support may exceed initial costs. For instance, it is often said that for complex and long-lived systems, such as weapon systems, buildings, and aircraft fleets, the operation and support cost accounted for as much as $75 \%$ of the total cost [7], [8]. Under the availability contracting arrangements, the responsibilities for the operational phase are transferred from the customer to the supplier (the OEMs), where associated technical, commercial, financial, and behavioral risks and uncertainties in the life cycle need to be considered as early as possible [9]. One of the primary aims of TLC is intended to make effective choices between alternatives based on a view of the long-term costs associated with each alternative. For instance, decisions can be based on tradeoffs between high capital cost investment for lower operation and maintenance costs [10]. Critically, the decisions made in the early concept stages before large capital acquisitions are committed will have the greatest impacts. For example, it is also commonly suggested in the literature that about $70 \%-80 \%$ of the cost of a product is committed in the early stages, although it may vary depending on the type of system [11]. Therefore, it will be a business advantage if costs associated with maintainability, supportability, and disposal can be taken into consideration earlier. The ability to understand uncertainty in the service costs is vital to the success of availability contracting [9]. Paradoxically, these early decisions also have to be made when uncertainty is greatest.

Uncertainty can be defined as "a potential deficiency in any phase or activity of the modeling process that is due to lack of 


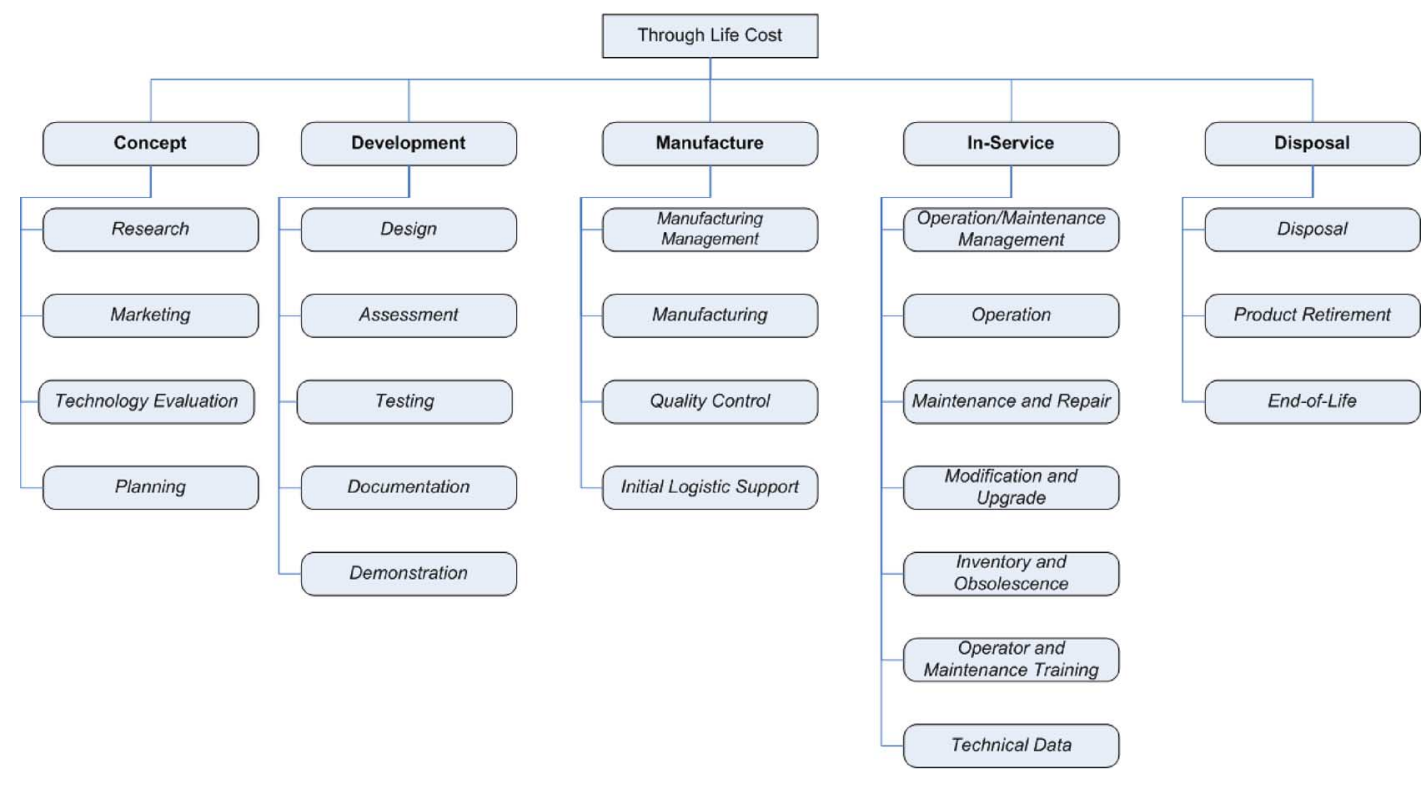

Fig. 1. LCC breakdown structure, adapted from [6] and [8].

knowledge which causes model-based predictions to differ from reality" [12], [13]. For example, an aircraft due for manufacture in 10-15 years can include uncertainty about new manufacturing processes, materials, and requirement changes. In particular, the operation and support costs related to such systems are very difficult to predict [8]. A number of large-scale and complex projects have been subjected to overexpenditure. Typical examples of cost overrun include the 2012 Olympics and the Airbus A380 [14], [15]. Much of the research to date has illustrated that this can be attributed to decisions made within the early design stages of a project. As a result, transparent and quantitative decisions based on costs are being encouraged throughout, both in the governmental and defense sectors. There is also the view that some estimates are deliberately low in domains such as large public infrastructure projects and aerospace/defense [14], [16]. Despite this view, the overriding concern is that estimates are extremely difficult and uncertainties within the estimates are not always clear [17].

The procedures for estimating TLC may include deciding on the cost elements of interest or, considered important, defining the cost breakdown structure (components of each element), developing cost estimation methodology (establish how costs for each component is to be estimated), and reviewing the results (validation and documentation of the analysis). The actual elements, structure of the model, and the methodology vary depending on the needs and scope of the analysis. For instance, a typical TLC breakdown for engineered products is shown in Fig. 1. Furthermore, TLC analysis can be performed at various levels depending on the information available and the type of analysis used [18]. For example, a generic framework for collecting WLC data at five levels for the building industry based on project, phase, category, element, and task is described [19]. Tools for estimating TLC ranges from bespoke spreadsheets to commercial-off-the-shelf (COTS) software such as SEER [20], PRICE [21], and Relex [22]. A more comprehen- sive review of software and TLC modeling approaches can be found in [23]. The U.S. DoD developed the cost analysis strategy assessment (CASA) as a software implementation to model the total costs from initial research to maintenance and in-service expenses [24]. These tools generally provide capability of modeling uncertainty but lack emphasis on how best to represent or manage the uncertainty. This paper provides a critical review of uncertainty in TLC estimation and discusses the requirement of a different approach for characterizing uncertainty in TLC to improve the decision making under conditions of uncertainty.

\section{LITERATURE REVIEW}

Uncertainty has been studied in a wide range of applications and domains. The emphasis given in this literature review is on those papers that address uncertainty understanding for the purpose of improving confidence in the modeling activities.

\section{A. Terminology and Classification}

Uncertainty may result due to various reasons, which Zimmermann [25] recognized as lack or abundance of information, conflicting evidence, measurement uncertainty, ambiguity, and belief (or subjectiveness). Uncertainty is affected by the quality and quantity of information. Various classifications of uncertainty have been proposed [26], but very little consensus has been achieved. Where consensus is achieved, it tends to be specific to certain domains or communities.

Isukapalli [27] and Du and Chen [28] distinguish between the parameter and model uncertainty, which is relevant in modeling activities. Model uncertainty is generally implied to be epistemic, mainly due to the lack of knowledge, complexity, and imprecision [12], [29]. Nilsen and Aven [30] further distinguish between model uncertainties as a result of lack of knowledge and deliberate simplifications due to economy and convenience. The selected model is generally a tradeoff between accuracy and 
detail, so that only that model needs to be developed that performs its required function. Parameter uncertainty may be introduced in the description of the parameters, such as in the physical or the properties parameters in engineering analysis [31]. The sources of parameter uncertainty are typically due to limited datasets, and empirical, subjective, and qualitative information.

Another useful classification of uncertainty that is widely accepted in engineering verification and validation $(V \& V)$ is the aleatory and epistemic uncertainty. Aleatory uncertainty is inherent variability that cannot be reduced by further measurement, although better sampling can improve knowledge about the variability. Epistemic uncertainty is caused by the lack of knowledge about the true value of a parameter or the behavior of a system and can be reduced by more accurate measurements or expert judgment. This distinction is useful in terms of selecting the suitable modeling methods, although some researchers argue that their separation may not be possible in reality [32]. Earl et al. [33] made a similar distinction, but referred to aleatory uncertainty as the known uncertainty (based on variability in past cases characterized as probability distributions) and epistemic uncertainty as the unknown uncertainty. Unknown uncertainties are those where the specific event or type of event could not have been foreseen. Others [34], [35] further distinguish between the internal and external uncertainties, stating that external uncertainties such as those driven by market and political variables are more difficult for a company to predict.

Uncertainties have been extensively considered within the context of LCA where uncertainty sources, types, and the modeling approaches have been studied in great detail by many authors [36]-[38]. Various classification schemes to describe uncertainty within LCA have also been proposed depending on the viewpoints of the researchers [36]. For instance, Huijbregts et al. [39] defined uncertainty in input data as parameter uncertainty, in normative choices as scenario uncertainty, and in mathematical relationships as model uncertainty. Heijungs and Huijbregts [36], [40] suggested that there are three broad types of uncertainties associated with each of the categories, i.e., no value, inappropriate value is available, and more than one value is available. Lloyd and Ries [41] adopted the same categorization and found from a survey that the parameter uncertainty was the type of uncertainty most frequently addressed in LCA. However, they cautioned that it was impossible to establish whether it was generally considered the most important. The Society of Environmental Toxicology and Chemist (SETAC) published a full report on data availability and quality issues in LCA [42]. These issues were considered to be important qualitative indication of uncertainty to the LCA decision makers.

\section{B. Uncertainty in Cost Estimation}

There are significant sources of uncertainties associated with the activities of cost estimation in general. At the time of estimation, the costing information available usually takes the form of historic product costs, and at times, there is a high degree of uncertainty [43], for instance, with regards to the form of the attributes (architecture, dimensions, and geometry) of the product and the knowledge concerning manufacturing processes [17].

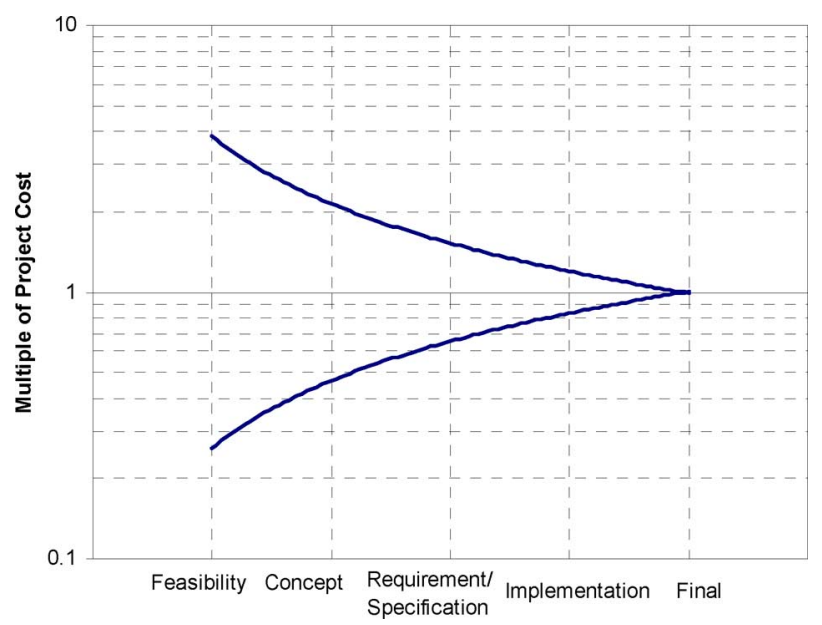

Fig. 2. Cone of uncertainty in software engineering projects [46], [47].

Creese and Moore [44] indicated that the cost estimates at the conceptual design stage are in the range of $-30 \%$ to $+50 \%$, which reduces to between $-5 \%$ and $+15 \%$ when the detailed design phase is entered. The uncertainty in cost estimation reduces, as more complete design information becomes available, including product design and manufacturing details, product support, reliability, and the disposal requirements [45]. In software engineering (see Fig. 2), the cone of uncertainty is typically used to illustrate variation in costs from the initial project phase of as much as a $\pm 400 \%$ error margin in the feasibility phase that gradually converges to the actual cost when software is released [46], [47].

Accurate cost estimation plays a significant role in the performance and effectiveness of a company as overestimation can result in loss of business and goodwill, whereas underestimation may also lead to financial loss to the company [8], [48]. In view of the significant uncertainty in costing of complex projects, the ability to estimate the costs with known uncertainty will provide grounds for making better decisions, and therefore, offer distinct engineering and business advantages [8], [49]. Although the need to understand uncertainty associated with cost estimation has been well articulated, cost estimation is still, in general, an open-loop process with limited efforts in providing correlation between the estimated and actual costs except perhaps for the overall value. The Research and Development (RAND) Corporation uses a cost-growth-factor (CGF) metric to relate the ratio of the final costs to the estimated costs at the Milestone II, engineering and manufacturing development (EMD) stage for DoD projects (see Fig. 3). From 44 projects, they found a systematic bias toward underestimating the costs (projects with CGF $>1$ ) and a substantial variation in estimating the final cost, suggesting low confidence in cost estimation [50].

$\mathrm{V} \& \mathrm{~V}$ is a systematic process used in computational analysis to provide evidence that predictions are credible and scientifically defendable. Uncertainty quantification is a significant part of the $\mathrm{V} \& \mathrm{~V}$ process. However, $\mathrm{V} \& \mathrm{~V}$ in cost estimation methods have not received a great deal of attention to date. In the same report by RAND Corporation, it is stated that there is little documentation in the open literature about what methods 


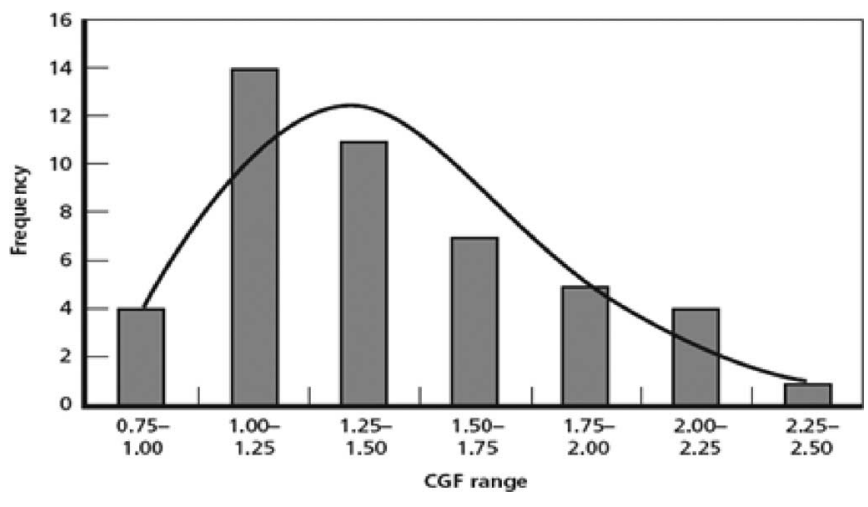

Fig. 3. Distribution of CGF [50].

have been used in specific cases, how accurate the methods have been overall, and for what different phases of the life cycle of completed projects where actual costs could be compared to predicted costs.

\section{UNCERTAINTY IN THROUGH-LIFE COSTING}

As opposed to traditional product costing, TLC encompasses a much greater scope, and therefore, uncertainty too. In particular, the nature of estimation deals with the future that is unknown, including costs associated with future scenarios such as the maintenance and operating regimes, technology obsolescence, or changes in legislation. It is, therefore, not surprising that the longer the life, the greater the uncertainty and the lower the validity of the WLC estimates [51]. The reasons for the lack of V\&V effort in TLC could include economic or practical difficulties in collecting the data required [52]. In particular, operating cost data for current equipment are not readily available, and if available, the data may not be accurate, complete, or representative [53]. Also, cost data may not be retained in useful and suitable formats to allow for a detailed and stepwise comparison between the estimated and actual costs. This is despite many researchers emphasizing the importance of a feedback loop [10], [54]. Furthermore, TLC typically involves large and extended models (several thousands of equations) embedded in spreadsheets. The use of spreadsheets means that the models are difficult to trace and manage, and are therefore, more susceptible to errors [17]. The widespread industrial use of spreadsheet-based costing is evident in European Life Performance (EUROLIFEFORM), a European collaborative project started in April 2001 [55]. Although software such as @Risk and Crystal Ball are used to provide probabilistic modeling of TLC and performance, these approaches do not readily lend themselves to validation.

In North Atlantic Treaty Organization's (NATO) 2007 report on methods and models for LCC, practical guidelines for validating cost models are provided [56]. The report suggests using more than one method of estimation, if possible, and the desirable criteria of model attributes should include the following, based on best practice recommended by the Society of Cost Estimating and Analysis (SCEA).
TABLE I

SUMMARY OF DATA UNCERTAINTY IN TLC

\begin{tabular}{|l|l|l|l|}
\hline $\begin{array}{l}\text { Data } \\
\text { Uncertainty }\end{array}$ & Source & Type & Example \\
\hline Variability & $\begin{array}{l}\text { Inherent } \\
\text { randomness }\end{array}$ & Aleatory & $\begin{array}{l}\text { Repair time, } \\
\text { Mean Time } \\
\text { Between Failure. }\end{array}$ \\
\hline $\begin{array}{l}\text { Statistical } \\
\text { error }\end{array}$ & Lack of data & Epistemic & $\begin{array}{l}\text { Scarce reliability } \\
\text { data. }\end{array}$ \\
\hline Vagueness & $\begin{array}{l}\text { Linguistic } \\
\text { uncertainty }\end{array}$ & Epistemic & $\begin{array}{l}\text { The component } \\
\text { needs to be } \\
\text { replaced about } \\
\text { every 2 to 3 } \\
\text { months. }\end{array}$ \\
\hline Ambiguity & $\begin{array}{l}\text { Multiple } \\
\text { sources of } \\
\text { data }\end{array}$ & Epistemic & $\begin{array}{l}\text { Expert 1 and } \\
\text { expert 2 provide } \\
\text { different values } \\
\text { to end-of-life } \\
\text { costs. }\end{array}$ \\
\hline $\begin{array}{l}\text { Subjective } \\
\text { judgement }\end{array}$ & $\begin{array}{l}\text { Optimism } \\
\text { bias }\end{array}$ & Epistemic & $\begin{array}{l}\text { Over confidence } \\
\text { in schedule } \\
\text { allocation. }\end{array}$ \\
\hline Imprecision & $\begin{array}{l}\text { Future } \\
\text { decision or } \\
\text { choice }\end{array}$ & Epistemic & Supplier A or B. \\
\hline
\end{tabular}

1) Accuracy: This includes good curve fits and minimal error bands, based on an assessment of the most likely costs.

2) Comprehensiveness: Level of detail, ground rules, and assumptions must be detailed in the documentation.

3) Replicability and auditability: References to source data, significance, and goodness-of-fit statistics for cost estimation relationships (CERs) clearly detailed calculations and results and rationale for method or reference chosen.

4) Traceability: This means traceable to source documentation.

The U.S. Government Accountability Office (GAO) has adopted similar criteria for validating cost estimates [57]. This development is an indication of the importance industries are placing on validation of TLC estimates to improve the use and understanding of uncertainty in the TLC decision-making process.

\section{A. Data Uncertainty}

The robustness of a cost estimate improves with the volume of information available [45], [58]. However, all the required data for conducting TLC may not be available at the estimation stage where decisions that influence TLC are taken and before commitment to significant capital expenditures is made. The three main types of data required are cost data, schedule or program data, and technical data [57]. In addition to data collection and assurance issues such as completeness, provenance, and reliability (internal or external databases), there is uncertainty in the data that are related to the levels of the available knowledge. Table I summarizes the typical sources and types of uncertainty in data for estimating TLC. The aleatory uncertainty mainly describes the inherent randomness. The epistemic 


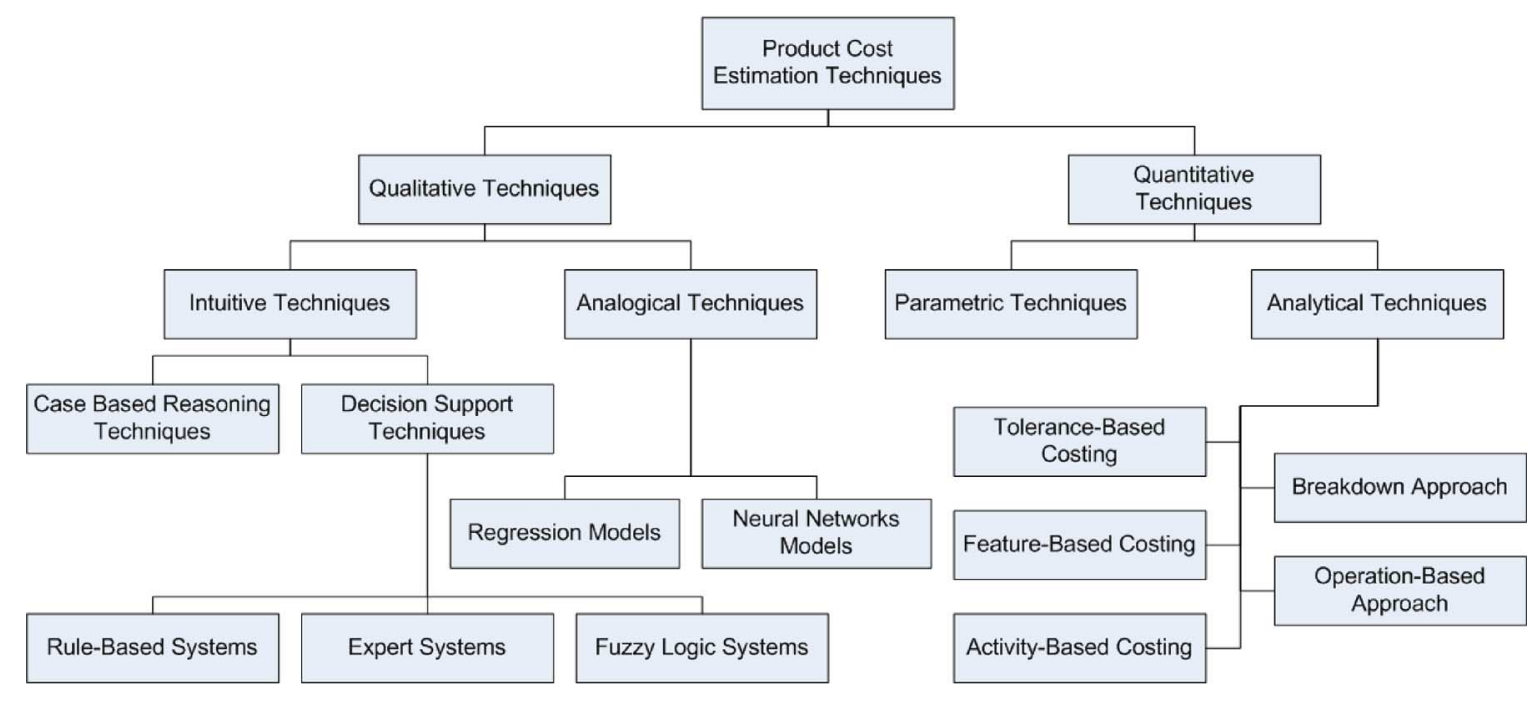

Fig. 4. Classification of cost estimation methods [63].

uncertainty can arise because of linguistic vagueness, ambiguity due to multiple sources of data, optimism bias [16], [50], [59], and imprecision associated with future decision. An example of imprecision could be the lack of knowledge about the manufacturing process to be used where the cost will be dependent on that decision (which may be influenced by technical constraints). The lack of statistical data can result in epistemic uncertainty about the underlying statistics. The standard error is related to sample size $n$ and probability $p$ by

$$
\text { standard error }=\sqrt{\frac{p(1-p)}{n}} .
$$

It is apparent that both types of epistemic and aleatory uncertainties are present in the data, and in particular, there is significant epistemic uncertainty.

\section{B. Model Uncertainty}

As with any modeling process, the estimation of TLC is based on the development of models that relate costs to certain input parameters. The input parameters may contain data uncertainty, as described earlier. The model, in turn, may also contain uncertainty, for example, due to the lack of definition, assumptions, or approximation (sometimes due to time pressure [57]), selection of cost estimation methods [57], level of detail [60], and complexity and correlation between cost elements [61]. Epistemic uncertainty may arise if there is a lack of definition for the purpose of developing the cost breakdown structure, or when the analysts have to make simplifying assumptions in the model to exclude elements deemed less important.

There are different methods for evaluating the TLC of a product or a system. The application of the appropriate technique is an important factor for the quality of the estimate. Some researchers have attempted to classify the various methods, but the categorization is not consistent [8], [62]. One of the more extensive classifications was proposed in [63], as shown in Fig. 4. According to the authors, cost estimation can be categorized as having qualitative and quantitative approaches, which can be further subdivided into two categories each. The resulting four categories, intuitive, analogical, parametric, and analytical (often referred to as the engineering approach [62]), are consistent with that proposed in [64] and [65]. This classification is based on similar characteristics of the methods and is used here to discuss uncertainty in the cost estimation methods. For supporting early cost estimation, Niazi et al. [63] suggested that fuzzy logic systems and neural network models inherently include uncertainty in them. Many researchers have also reported on the suitability of these techniques to different life cycle phases [64], [66], but only Chen et al. [67] have attempted to subjectively assign the uncertainty in cost estimation methods using three levels: low, medium, and high. However, they did not provide details on how these levels were established.

1) Intuitive Techniques: The intuitive technique is sometimes referred to as an expert opinion approach. As a qualitative method, the technique significantly relies on the knowledge and experience of the experts to estimate probable costs. Therefore, approaches for increasing reliability of estimation from experts must be considered [68]. The major form of uncertainty is epistemic, in the experts' formulation of rules of thumb and qualitative evaluation of similarities between systems.

2) Analogical Techniques: The analogical method adjusts the cost of a similar existing program/system to estimate for a new program/system. Cost data are subjectively adjusted based on judgment of how similar or different the new system is to the existing one in terms of complexity, size and scope, technology, system architecture, socioeconomic situation, etc. Although the method may utilize quantitative analysis such as regression, it involves subjective evaluation of the factors that have an impact on cost. The approach can be used at different levels of the system such as comparing between subsystems. For this method, uncertainty reduces if there is high similarity between the two systems. An example using historical cost growth of projects to estimate a growth rate for current similar projects is illustrated by RAND Corporation [50]. The CGF is analyzed by taking the ratio of final cost to initial cost estimate and then applying 
simple linear regression. In constructive systems engineering cost model (COSYSMO), cost multipliers are used to scale the system engineering effort to reflect technological maturity, readiness, and obsolescence relative to that of nominal systems [69]. Again, the major type of uncertainty in using this method is the epistemic uncertainty.

3) Parametric Cost Estimation: Parametric techniques apply statistical methods such as regression analysis to relate cost to a number of constituent variables called cost drivers using historical data and mathematical expressions. The cost drivers could be any parameters that are key determinants of cost, such as weight and volume. The mathematical expressions are also known as CERs and can take various forms depending on the characteristics of the relationship. The most usual mathematical forms are the linear form and the power form [70]. A number of statistical properties of the regression equation can be used to indicate the quality of the CER, including the confidence interval and normalized sum of residual error [70]. The main indicator of uncertainty in CERs is often based on the square of the correlation coefficient, $r^{2}$, which denotes the strength of correlation between the independent and dependent variables. The value of $r^{2}$ ranges from 0 to 1 , with 0 indicating no correlation and 1 indicating a perfect correlation. Farineau et al. [71] proposed an extensive selection method based on statistical regression quality and technical coherence that are weighted and then combined.

Uncertainty in parametric cost estimation is dependent on the uncertainty in the historical data and the CER used. The values of the cost drivers may be difficult to define accurately and might evolve due to changing requirements over the program's life [50]. Thus, the estimator must make some judgments about which parameters are relevant and should be included, and which values to use. For instance, the data used to derive the CER often need to be adjusted against inflation, economic conditions, and technological differences [60], [72]. Also, the CERs are valid only for a limited range; extrapolation outside the validity range may cause serious errors in the estimate. The choice of CER is very important because there may be step changes in the relationship such that different functions may be required for the range considered. For example, the fabrication cost for aircraft T-stringers in Fig. 5 is shown to vary linearly with the stringer length. However, if there is a step change in the costs associated with longer stringers (more than $5000 \mathrm{~mm}$ ) compared with shorter ones (below $2000 \mathrm{~mm}$ ), the effect may not have been captured effectively by a single CER. Mileham et al. [73] used three CERs to capture the cost-weight relationships of acrylonitrile butadiene (ABS) injection moldings for different weight bands. In addition, the CERs do not capture the uncertainties in the values of the cost drivers, which can have an important effect on the final cost. All of these cause uncertainties in the estimation from parametric methods.

4) Analytical Techniques: The analytical techniques are sometimes referred to as the engineering approach or "bottomup" method. The work breakdown structure (WBS) is usually used to provide a detailed hierarchical decomposition of cost elements, which are evaluated analytically. A WBS is a hierarchical list of all items that must be paid for to bring a system to

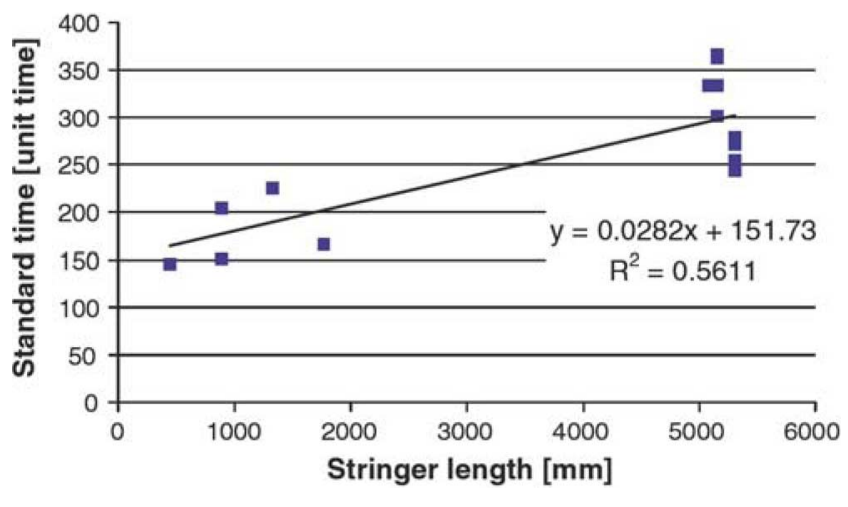

Fig. 5. Fabrication cost for aircraft stringers [74].

its full operational capability, such as for a space system shown in Fig. 6.

Various WBS can be used depending on the problem in hand, including operation-based, feature-based, and activity-based. The analytical methods require significantly more development effort and data to populate, and hence, are seldom practical in early life cycle phases. The uncertainty in analytical methods depends on the scope and the level of details considered in the WBS. The greater the scope of the model, the more uncertainty is anticipated as the uncertainty is aggregated from each of the elements. It is also possible that data may not be available to characterize all elements of the WBS to the same level of fidelity. Generally, the more details considered, the more accurate the model becomes, but any simplification may cause epistemic uncertainty in the cost estimation. One of the main sources of uncertainty in the analytical methods is the consideration of dependency between elements in the WBS [75]. Failure to characterize the dependency will introduce significant uncertainty to the cost estimate [61]. Also, uncertainty may result from complexity; therefore, system engineering and integration efforts need to be accounted for separately.

5) Extrapolation From Actual Costs: Extrapolation can be performed on cost data that are collected from prototype systems and the previous life cycle phases. As opposed to analogical and parametric approaches that are based on costs of previous systems, the extrapolation is done on actual cost of the current system. This method will generally be preferred over other methods because it provides the most reliable cost estimation, provided the actual cost incurred is known [76]. For instance, quotation from the suppliers can be used to estimate the final costs of the whole system. The main source of uncertainty in this method arises from any changes in the conditions during the extrapolation process. For instance, if the supplier changes for an unforeseen reason or the production process changes from the prototype system, then these may have significant effects on the estimated costs. The main drawback of this technique is the late availability of actual cost data, and is therefore, difficult to accomplish in the early acquisition or design phase.

The methods for estimating costs are not mutually exclusive and more than one approach is usually adopted at any given time to establish the cost of a system. Some hybrid approaches have also been proposed (for example, see [77]). In these hybrid 


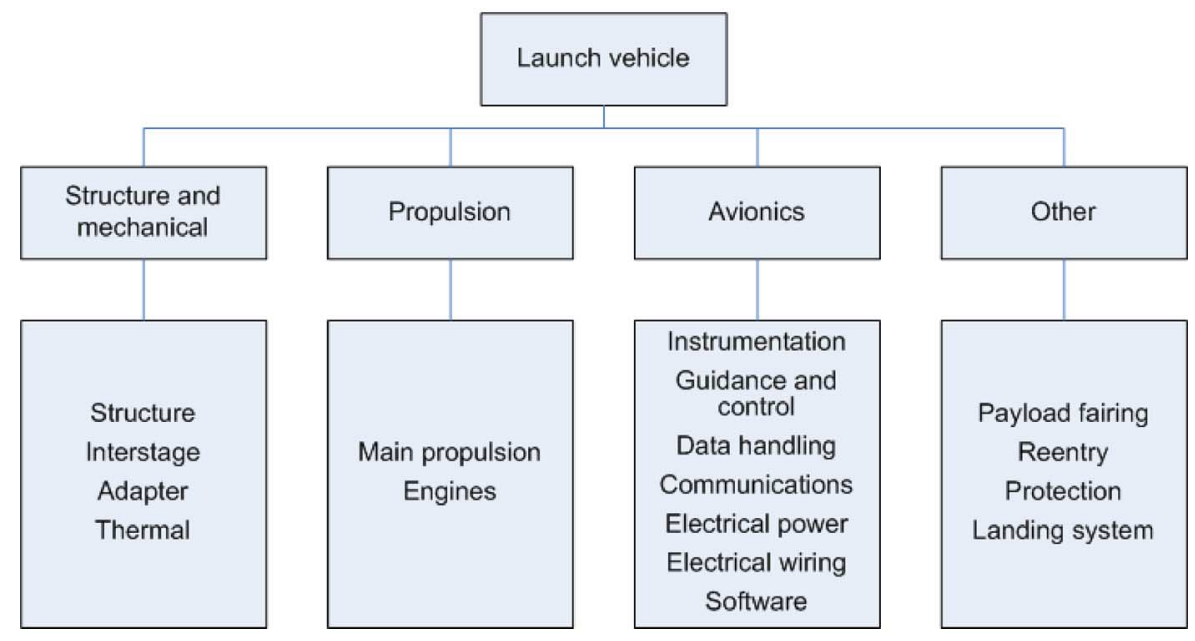

Fig. 6. WBS for a space system launch vehicle [75].

TABLE II

SuMmaRy OF UNCERTAINTY AsSOCIATED With COST ESTIMATION TECHNIQUES

\begin{tabular}{|l|l|l|}
\hline $\begin{array}{l}\text { Cost estimation } \\
\text { methods }\end{array}$ & $\begin{array}{l}\text { Sources of } \\
\text { uncertainty }\end{array}$ & Uncertainty \\
\hline $\begin{array}{l}\text { Intuitive/expert } \\
\text { opinion }\end{array}$ & Judgement & Epistemic \\
\hline Analogical & $\begin{array}{l}\text { Selection of } \\
\text { benchmark model } \\
\text { (qualitative } \\
\text { characteristics) }\end{array}$ & Epistemic \\
\hline Parametric & $\begin{array}{l}\text { Cost } \\
\text { drivers/parameters } \\
\text { CER choice } \\
\text { Regression fit } \\
\text { Data uncertainty } \\
\text { Extrapolation }\end{array}$ & Epistemic \\
\hline Analytical/engineering & $\begin{array}{l}\text { Scope } \\
\text { Level of details } \\
\text { Available data }\end{array}$ & Epistemic \\
\hline $\begin{array}{l}\text { Extrapolation from } \\
\text { actual costs }\end{array}$ & $\begin{array}{l}\text { Changes in } \\
\text { conditions } \\
\text { Limited data }\end{array}$ & Epistemic \\
\hline
\end{tabular}

approaches, the characteristics of uncertainty are similar to the individual methods used. A summary of the main sources and types of uncertainty associated with cost estimation techniques is given in Table II.

\section{Scenario Uncertainty}

As TLC estimation inherently deals with events and conditions that are long-term, scenario uncertainty is one of the main sources of uncertainty. Scenario-based approaches involve predicting a series of decisions and events that might occur in the future, which will affect the TLC, such as the introduction of new technologies, changes in technical requirements, introduction of new legislations, and supply chain disruption. Typically, these events affect both external and internal business models and conditions, and it is difficult to accurately forecast the magnitude of these changes because they are influenced by, for example, the economic conditions, labor relations, and inflation (external uncertainty). These changes in the external conditions make a direct comparison of estimated costs and the actual costs incurred through life more difficult.

A related and commonly used concept is risk, where marketrelated, technical and operational, as well as institutional uncertainties [78] may ultimately result in additional costs in the life cycle. Changes in technical specifications such as the performance levels and life expectancy often have significant impacts on the actual TLC of a system. An example is the changes in requirements for the Royal Australian Air Force (RAAF) F-111 program, leading to significantly higher costs to the Australian Government. The SA80-A1 weapon systems developed based on fighting in the temperate climates of northwest Europe needed an upgrade when deployed in the Gulf War [79]. These changes are particularly difficult to forecast at the early life cycle stages given the lack of knowledge, and hence, scenario uncertainty is mainly epistemic in nature. Scenario uncertainty can be associated with situations where the different alternatives are predicted under the fact that which alternative will be realized in practice is not known. Nonetheless, some techniques have been developed to forecast technology obsolescence and design refresh, and can be used to reduce the associated uncertainty [80]. At present, scenario uncertainty is dealt with by modeling a single event/episode from a given set of inputs multiple times to assess uncertainty deterministically. The scenarios may correspond to pessimistic, anticipated, and optimistic estimates [50]. Alternatively, each scenario may be assigned probability (e.g., 1 in 10 years) to reflect experts' belief of the likelihood of each scenario.

Table III presents some common uncertainties encountered throughout the life cycle phases.

\section{UNCERTAINTY REPRESENTATION AND MODELING}

Uncertainty representation and modeling are methods for incorporating quantitative uncertainty into the cost estimates. 
TABLE III

UNCERTAINTIES IN THE LIFE CYCLE PHASES

\begin{tabular}{|c|c|c|c|c|c|}
\hline \multirow{2}{*}{$\begin{array}{l}\text { Nature of } \\
\text { uncertainty }\end{array}$} & \multicolumn{5}{|l|}{ Life Cycle Phase } \\
\hline & Concept & Development & Manufacture & In-Service & Disposal \\
\hline Epistemic & $\begin{array}{l}\text { Requirement } \\
\text { changes } \\
\text { Design } \\
\text { alternatives } \\
\text { Technology } \\
\text { maturity } \\
\text { Funding } \\
\text { availability } \\
\text { Performance } \\
\text { indicators } \\
\text { Discount rate }\end{array}$ & $\begin{array}{l}\text { Design changes } \\
\text { Demonstration } \\
\text { programme } \\
\text { Complexity } \\
\text { Testing regime }\end{array}$ & $\begin{array}{l}\text { Process selection } \\
\text { Manufacturing } \\
\text { technology } \\
\text { Choice of suppliers } \\
\text { Tooling required }\end{array}$ & $\begin{array}{l}\text { In-service date } \\
\text { Technology } \\
\text { obsolescence } \\
\text { Design refresh } \\
\text { Maintainability } \\
\text { Supply chain } \\
\text { disruption } \\
\text { Logistics options } \\
\text { Location of repair } \\
\text { Warranty and liability }\end{array}$ & $\begin{array}{l}\text { New legislation } \\
\text { Recycling } \\
\text { technology } \\
\text { Disposal means } \\
\text { (recycle, } \\
\text { remanufacture, } \\
\text { discard) }\end{array}$ \\
\hline Aleatory & Market demand & $\begin{array}{l}\text { Development time } \\
\text { System performance } \\
\text { Learning rate } \\
\text { Measurement error } \\
\text { System reliability } \\
\text { and life }\end{array}$ & $\begin{array}{l}\text { Overheads } \\
\text { Production rate } \\
\text { Labour hours and } \\
\text { rates } \\
\text { Scrap rates } \\
\text { Material costs } \\
\text { Process capability } \\
\text { Material performance }\end{array}$ & $\begin{array}{l}\text { Maintenance cost } \\
\text { (repair time, material) } \\
\text { Operational } \\
\text { conditions } \\
\text { Operational overheads } \\
\text { (fuel, taxes) } \\
\text { Spares demand } \\
\text { Failure rates } \\
\text { Remaining life } \\
\end{array}$ & $\begin{array}{l}\text { End of life value } \\
\text { Disassembly time }\end{array}$ \\
\hline
\end{tabular}

\section{A. Approaches for Modeling Uncertainty}

Various methods have been proposed for characterizing uncertainty in cost estimation. Many of the methods are based on probability theory [50], [81]. Two fundamentally different approaches in probability theory have been employed for this purpose. In cases where historical data are available, the analysts will derive suitable probability density functions (pdfs) to characterize the cost parameters. Historical data can be derived from various information sources, e.g., heuristics, internal, or external databases (supplier and industrial). The Monte Carlo simulation is a popular computational method to propagate variability in the input parameters to estimate variability in the output parameters. Analytical methods such as sensitivity analysis and method of moments are also typically employed [50]. Although the probabilistic methods deal very well with variability (aleatory uncertainty), large amounts of data are usually required to derive the pdfs that may not be available at the estimation stage and early in the life cycle. For example, accurate and dependable cost data for new equipment are often difficult to acquire, especially for new technologies [53].

An alternative interpretation of probability is to use subjective probability that is popular for characterizing uncertainty using the experts' opinion. The RAND Corporation reports on methods to model cost uncertainties and interpreting risk (should not be confused with technical risk) from it [68]. The approach usually focuses on using single and ranges of values, for example, three point estimates to construct the pdfs so that the probabilistic methods can be used. For instance, triangular distributions are commonly used to characterize the minimum, most likely, and maximum points. Subjective estimates may introduce bias and imprecision, including, e.g., overoptimism in expert judgment and the representativeness of historical data resulting in estimation error. As a result, elicitation of subjective probability from experts is often a lengthy and intensive process to improve the robustness of estimates obtained in this manner. For instance, the Delphi technique is typically used to iteratively converge the experts' opinion [68], [82].

Due to a lack of statistical cost data and the existence of epistemic uncertainty, it is suggested that alternative uncertainty theories and models may be more suitable than the probability theory for handling uncertainty. For instance, Kishk [83] suggested the different types of uncertainties in WLC modeling (see Fig. 7) and proposed a transformation approach to combine the probability and fuzzy set descriptions of uncertainties. Fuzzy sets have been used to represent the concept of plausibility in possibility theory, where fuzzy measures provide the upper bounds on probability [84]. Generally, uncertainty theories such as probability and fuzzy set theories are based on different terms of reference [25], and therefore, the combination will result in changes in information content [85].

From the previous sections, it is apparent that both epistemic and aleatory uncertainties may exist in the cost data, model, and scenario description; therefore, methods for dealing with both types of uncertainties in cost estimation will be useful. Some researchers have suggested that the representation of possibility and fuzzy set appears to be more pragmatic and intuitive to elicit from experts when judgment is required [86]. Interval numbers have also been used to characterize uncertainty when the underlying pdf is unknown within range values [87]. The interval numbers represent the range of parameter values by the lower and upper bounds and have been used to model epistemic uncertainty in engineering design [88]. In LCC analysis, Kang and Brissaud [89] used intervals to represent imprecise end-of-life data. Due to lower information requirement, interval and fuzzy 


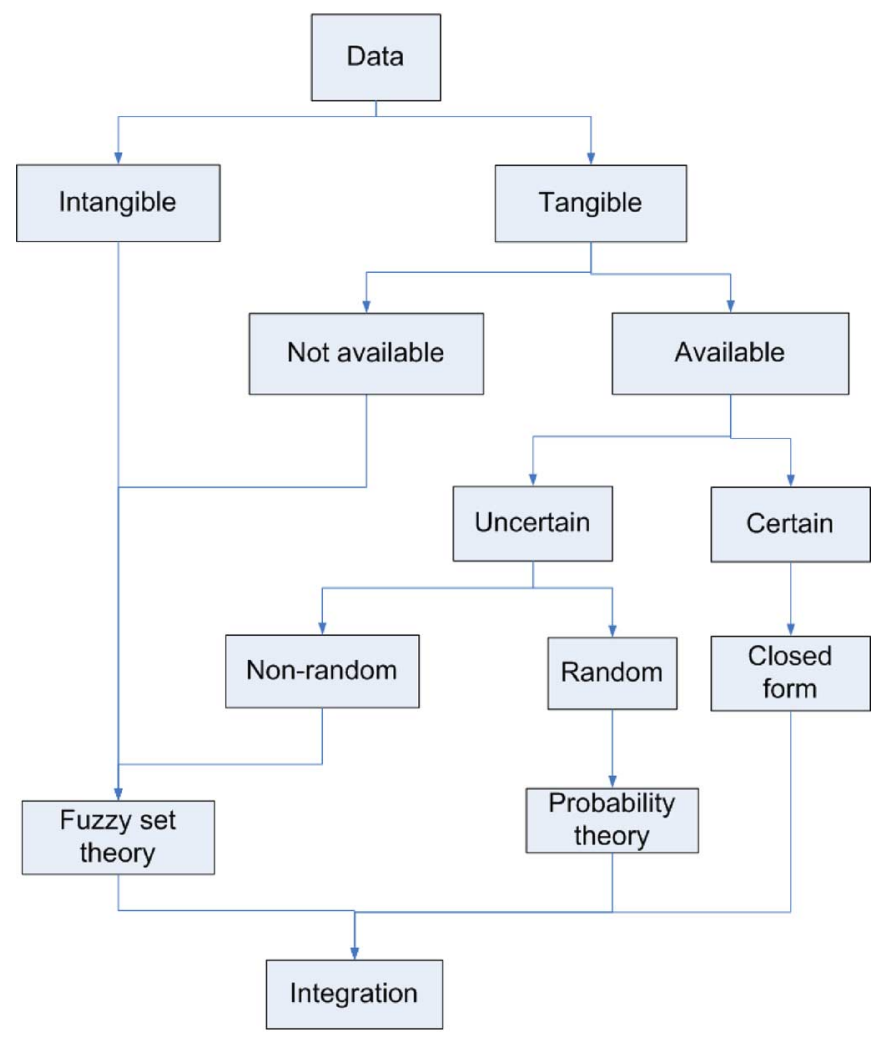

Fig. 7. Handling uncertainties in WLC modeling [83].

methods are often useful in estimation where data are limited, vague, ambiguous, or imprecise [41], [90]. Others have defended the probability approach as the most suitable representation for both aleatory and epistemic uncertainties [91]. However, they admitted that the elicitation process is critical because of imprecision in probability judgments. Hence, the choice of probability or alternative representations using interval and fuzzy set should depend on whether reliable and defendable pdfs can be elicited from the experts and whether the resource commitment is justifiable. In the authors' opinion, the methods suitable to characterize different types of cost uncertainties have not been rigorously investigated and warrant further research. This view will allow distinguishing between information that is knowable in the future and those that are inherently variable in the system.

\section{B. Discussion and Perspectives}

In estimating TLC, analysts often need to translate subjective uncertainty into objective measures in order to arrive at quantitative measures of cost uncertainty. This process is inherently uncertain. Examples include using risk scores to relate risk of technology, software maturity, etc., to cost estimation uncertainty [57], [69]. As mentioned previously, most of the modeling approaches are based on probability theory and focus on the representation of uncertainty using pdfs. Some heuristics have also been developed to augment the pdf to account for imprecision (see [75]). Most of the commercial cost modeling tools also include an uncertainty modeling capability such as sensitivity analysis and Monte Carlo simulation exclusively for

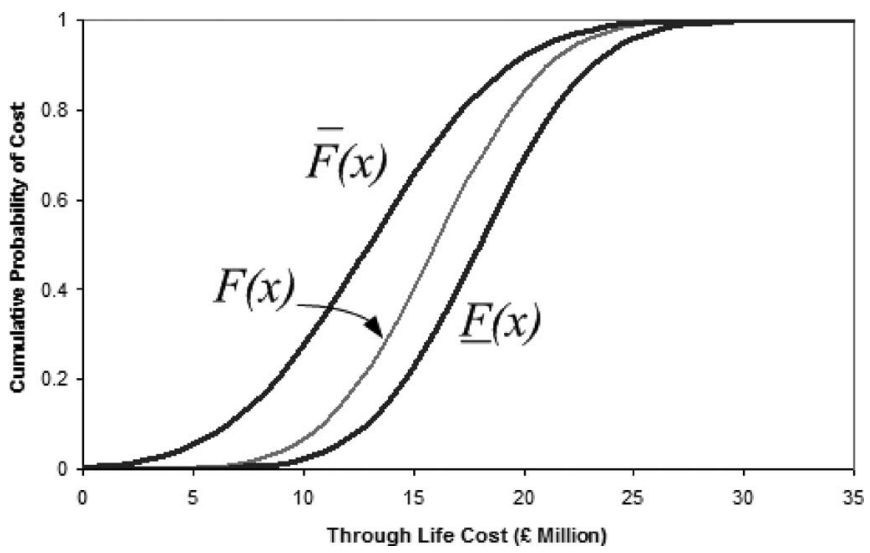

Fig. 8. Imprecise probability representation.

modeling variability by allowing for the input parameters to be defined as pdfs.

Uncertainty in TLC may be aleatory or epistemic in nature, in many aspects dominated by lack of knowledge in the data, model, and scenario description. It may be required that both aleatory and epistemic uncertainties are considered simultaneously, for example, where the input parameter uncertainty is aleatory but model uncertainty is epistemic. The separation of epistemic and aleatory uncertainties is important in terms of modeling because different theories and representation are suitable for different kinds of uncertainty [92], [93]. It is suggested that a different approach will be required to characterize them separately because in principle, the portion of the uncertainty in the models' outputs that is due to epistemic sources of uncertainty is reducible, whereas the portion due to aleatory uncertainties is irreducible [91].

To this end, a more generalized form of probability theory is identified as a potentially useful representation for expressing combined uncertainties as imprecise probability [94]. The imprecise probability provides information about the probability bounds or a set of probabilities in a single construct. In probability bounds analysis [95], an interval-type bounds on cumulative density functions (cdfs), also called the probability or p-boxes, are defined for nondecreasing functions $F(x)$, with $x$ being from $\Re$ into $[0,1]$ such that $\underline{F}(x) \leq F(x) \leq \bar{F}(x)$, as

$$
F^{\text {box }}(x)=[\underline{F}(x), \bar{F}(x)]
$$

where $\underline{F}(x) \leq \bar{F}(x)$ for all $x$ in $\Re$ and

$$
\begin{aligned}
& \underline{F}(x)=\text { lower cdf } \\
& \bar{F}(x)=\text { upper cdf. }
\end{aligned}
$$

A simple p-box is a region bounded by two cdfs, as illustrated in Fig. 8; the p-box will degenerate to a precise cdf when the information is detailed enough to specify a distribution completely. A more detailed explanation of the characteristics of p-box can be found in [95] and [96].

Some researchers have used this representation to incorporate the uncertainty caused by lack of knowledge and variability in engineering design and risk analysis [96], [97]. The epistemic uncertainty is characterized by the interval bounds/sets of cdf 
and variability is characterized by the cdf. The $\mathrm{p}$-box representation provides means to include conservatism (through the lower and upper bounds) without having to make assumptions about the statistical independence and the actual distributions within the bounds [94], [96]. The imprecise probability appears to be a reasonable representation when both epistemic and aleatory uncertainties are present in TLC, for instance, alternative life cycle scenarios can be modeled as sets or ambiguous expert opinions as intervals of probabilities. However, their values will need to be investigated in terms of enhancing TLC decision making and also in terms of their ability to explicitly quantify uncertainties in costing problems.

Distinguishing between epistemic and aleatory uncertainties is also important in the context of decision making, often recognized as decision under risk and decision under uncertainty in decision theory [98]. The former is a situation dealing with decision making where the probabilities of the possible outcomes are known, whereas the latter with situations when it may be inappropriate or impossible to assign probabilities to the outcomes. Typical decisions informed by the LCC analysis include the evaluation of different investment scenarios or choice between alternative designs for the whole or part of a constructed asset [18]. Decisions associated with TLC are also often complicated by competing requirements; therefore, methods for dealing with multicriteria decision making under uncertainty will be required [59]. If uncertainty associated with each outcome can be precisely described using probability representation, then the expected utility for that decision can be maximized. Under the conditions of uncertainty (lack of knowledge), because of imprecision, the desired optimal outcome may not always be determinate [99]. Several methods for dealing with this situation have been proposed, e.g., maximin-maximax rule, Hurwicz criterion [100], and information gap decision theory [101]. These methods have also been applied where both risk and uncertainty are present (for example, see [102] and [103]).

It is argued that although the current probabilistic cost risk analysis approach may implicitly incorporate the lack of knowledge in the construct of pdf, the construct does not allow for the risk and uncertainty components to be separated easily, thus convolving the ability to make informed judgments. Furthermore, understanding the types of uncertainty can more effectively focus efforts on V\&V. For example, the maintenance and service life is inherently probabilistic in nature and can be related to factors such as the mean time between failures (MTBF), cost of warranty, and reliability and repairs [49], [53]. Therefore, characterization of statistical confidence and data collection should be expanded in this area. If epistemic uncertainty in the cost estimation methods is high, then efforts should be expanded to enhance accuracy (add details, cross validation), improve expert judgment, etc.

\section{CONCLUSION}

This paper has reviewed uncertainty in TLC and concluded that epistemic uncertainty is an important component of cost estimation uncertainty. The present approach to TLC under uncertainty is to quantify the uncertainty in the probabilistic sense, using pdfs as the representation of uncertainty. It is suggested that the separation of aleatory and epistemic uncertainty should be made such that suitable representation and methods can be used to model the uncertainties faithfully. This distinction also allows for anticipation of information that is knowable in the future to update the estimates. It has been identified that a generic approach that can handle a combination of aleatory and epistemic uncertainties will be useful. The imprecise probability may be a suitable representation for such purpose; however, the ability in quantifying aspects of the epistemic and aleatory uncertainties in TLC needs to be further investigated. This will include prioritization of areas where each type of uncertainty is critical so that suitable actions for improving the uncertainty quantification and modeling can be taken. The resulting uncertainty representation will need to be interpreted in the context of decision making associated with TLC, for instance, in terms of decision under risk and uncertainty and deriving strategies to deal with them. Informed by this review, the research aims to provide a framework to manage uncertainties in TLC decision making.

\section{REFERENCES}

[1] W. M. Cheung, R. Marsh, L. B. Newnes, A. R. Mileham, and J. D. Lanham, "Standards and inference of design information in through life costing of innovative defence electronic products," Proc. IMechE B, J. Eng. Manuf., vol. 223, no. 2, pp. 169-181, 2009.

[2] R. J. Cole and E. Sterner, "Reconciling theory and practice of life-cycle costing," Build. Res. Inf., vol. 28, no. 5/6, pp. 368-375, 2000.

[3] G. Norris, "Integrating life cycle cost analysis and LCA," Int. J. LCA, vol. 6, no. 2, pp. 118-121, 2001.

[4] A. Little, Total Cost Assessment Methodology. New York: Amer. Inst. Chem. Eng., 1999.

[5] U.S. Department of Defense, Performance Based Logistics: A Program Manager's Product Support. Fort Belvoir, VA: Def. Acquisition Univ. Press, 2005.

[6] Through Life Capability Management, Ministry of Defence, Acquisition Operating Framework (AOF), U.K., Dec. 2008.

[7] G. Clark, P. Piperias, and R. Traill, "Life-cycle cost/capability analysis for defence systems," presented at the Simul. Tech. Training Conf. (SimTecT), Melbourne, Vic., Australia, 1999.

[8] Y. Asiedu and P. Gu, "Product life cycle cost analysis: State of the art review," Int. J. Prod. Res., vol. 36, no. 4, pp. 883-908, 1998.

[9] J. A. Erkoyuncu, R. Roy, E. Shehab, and P. Wardle, "Uncertainty challenges in service cost estimation for product-service systems in the aerospace and defence industries," presented at the CIRP IPS2 Conf., Cranfield, U.K., 2009.

[10] D. G. Woodward, "Life cycle costing-Theory, information acquisition and application," Int. J. Proj. Manage., vol. 15, no. 6, pp. 335-344, 1997.

[11] C. Rush and R. Roy, "Analysis of cost estimating processes used within a concurrent engineering environment throughout a product life cycle," presented at the Int. Conf. Concurrent Eng. 2000, Lyon, France.

[12] W. L. Oberkampf, S. DeLand, B. Rutherford, K. Diegert, and K. Alvin, "A new methodology for the estimation of total uncertainty in computational simulation," presented at the AIAA/ASME/ASCE/AHS/ASC SSDM Conf. Exhib., St. Louis, MO, 1999.

[13] D. A. DeLaurentis, "A probabilistic approach to aircraft design emphasizing stability and control uncertainties," Ph.D. dissertation, Georgia Tech., Atlanta, 1998.

[14] BBC, "MPs criticise rising 2012 costs," BBC News, London, U.K., 2008.

[15] BBC, "Airbus hikes A380 break-even mark," BBC News, London, U.K., 2006.

[16] B. Flyvbjerg, M. S. Holm, and S. Buhl, "Underestimating costs in public works projects error or lie?" J. Amer. Plan. Assoc., vol. 68, no. 3, pp. 279-295, 2002.

[17] J. Scanlan, A. Rao, C. Bru, P. Hale, and R. Marsh, "DATUM project: Cost estimating environment for support of aerospace design decision making," J. Aircraft, vol. 43, no. 4, pp. 1022-1028, 2006. 
[18] Buildings and Constructed Assets-Service Life Planning-Part 5: Life Cycle Costing, British Standards BS ISO 15686-5:2008, 2008.

[19] M. A. El-Haram, S. Marenjak, and M. W. Horner, "Development of a generic framework for collecting whole life cost data for the building industry," J. Qual. Mainten. Eng., vol. 8, no. 2, pp. 144-151, 2002.

[20] Golorath. (2008). SEER [Online]. Available: http://www.galorath.com

[21] Price Systems. (2008). TruePlanning [Online]. Available: http://www. pricesystems.com

[22] Relex Software Corp. (2009). Relex Reliability Studio [Online]. Available: http://www.relexsoftware.co.uk

[23] L. B. Newnes, A. R. Mileham, W. M. Cheung, R. Marsh, J. D. Lanham, M. E. Saravi, and R. W. Bradbery, "Predicting the whole-life cost of a product at the conceptual design stage," J. Eng. Des., vol. 19, no. 2, pp. 99-112, 2008.

[24] CASA, "Cost analysis strategy assessment (CASA) total ownership cost model," U.S. Army Logistics Support Activity, Aug. 2009.

[25] H.-J. Zimmermann, "An application-oriented view of modeling uncertainty," Eur. J. Oper. Res., vol. 122, pp. 190-198, 2000.

[26] B. M. Ayyub, Elicitation of Expert Opinions for Uncertainty and Risks: Theory, Applications and Guidance. West Palm Beach, FL: CRC Press, 2001.

[27] S. S. Isukapalli, "Uncertainty analysis of transport-transformation models," Ph.D. dissertation, State Univ. New Jersey, New Brunswick, 1999.

[28] X. Du and W. Chen, "Methodology for managing the effect of uncertainty in simulation-based design," AIAA J., vol. 38, no. 8, pp. 1471-1478, 2000.

[29] K. B. Laskey, "Model uncertainty: Theory and practical implications," IEEE Trans Syst., Man, Cybern. A, Syst., Humans, vol. 26, no. 3, pp. 340348, May 1996.

[30] T. Nilsen and T. Aven, "Models and model uncertainty in the context of risk analysis," Rel. Eng. Syst. Saf., vol. 79, pp. 309-317, 2003.

[31] R. G. Hills and T. G. Trucano, "Statistical validation of engineering and scientific models: Background," Sandia Nat. Lab., Albuquerque, NM, Tech. Rep. SAND99-1256, May 1999.

[32] E. Zio, "Two methods for the structured assessment of model uncertainty by experts in performance assessments of radioactive waste repositories," Rel. Eng. Syst. Saf., vol. 54, no. 2, pp. 225-241, 1996.

[33] C. Earl, J. Johnson, and C. Eckert, "Complexity," in Design Process Improvement-A Review of Current Practice, J. Clarkson and C. Eckert, Eds. London, U.K.: Springer-Verlag, 2005.

[34] O. de Weck, C. Eckert, and J. Clarkson, "A classification of uncertainty for early product and system design," presented at the ICED 2007, Paris, France.

[35] M. Greenberg, H. Mayer, and D. Lewis, "Life-cycle cost in a highly uncertain economic environment: The case of managing the U.S. Department of Energy's nuclear waste legacy," Fed. Facil. Environ. J., vol. 15, pp. 67-82, 2004.

[36] R. Heijungs and M. A. J. Huijbregts, "A review of approaches to treat uncertainty in LCA," presented at the IEMSS, Osnabruck, Germany, 2004.

[37] A. E. Björklund, "Survey of approaches to improve reliability in LCA," Int. J. LCA, vol. 7, no. 2, pp. 64-72, 2002.

[38] G. Geisler, S. Hellweg, and K. Hungerbühler, "Uncertainty analysis in life cycle assessment (LCA): Case study on plant protection products and implications for decision making," Int. J. LCA, vol. 10, no. 3, pp. 192.1192.3, 2005.

[39] M. A. J. Huijbregts, W. Gilijamse, A. M. J. Ragas, and L. Reijnders, "Evaluating uncertainty in environmental life-cycle assessment. A case study comparing two insulation options for a Dutch one-family dwelling," Environ. Sci. Technol., vol. 37, no. 11, pp. 2600-2608, 2003.

[40] R. Bretz, "SETAC LCA Workgroup: Data availability and data quality," Int. J. LCA, vol. 3, no. 3, pp. 121-123, 1998.

[41] S. M. Lloyd and R. Ries, "Characterizing, propagating, and analyzing uncertainty in life-cycle assessment: A survey of quantitative approaches," J. Ind. Ecol., vol. 11, no. 1, pp. 161-179, 2007.

[42] A. de Beaufort-Langeveld, R. Bretz, R. Hischier, M. Huijbregts, P. Jean, T. Tanner, and G. van Hoof, Code of Life Cycle Inventory Practice. Brussels, Belgium: Soc. Environ. Toxicol. Chem., 2003.

[43] H. Hosseini-Nasab, "Product cost estimating at the conceptual stage of design," Ph.D. dissertation, Dept. Mech. Eng., Univ. Bath, Bath, U.K., 2002.

[44] R. C. Creese and L. Moore, "Cost modelling for concurrent engineering," Cost Eng., vol. 32, no. 6, pp. 23-27, 1990.

[45] J. Corbett, "Design for economic manufacture," Ann. CIRP, vol. 35, no. 1, pp. 93-97, 1986.
[46] B. W. Boehm, Software Engineering Economics. Englewood Cliffs, NJ: Prentice-Hall, 1981.

[47] S. McConnell, Software Estimation: Demystifying the Black Art. Redmond, WA: Microsoft Press, 2006.

[48] J. M. Daschbach and H. Apgar, "Design analysis through techniques of parametric cost estimation," Eng. Costs Prod. Econ., vol. 14, no. 2, pp. 87-93, 1988.

[49] A. Kleyner and P. Sandborn, "Minimizing life cycle cost by managing product reliability via validation plan and warranty return cost," Int. J. Prod. Econ., vol. 112, pp. 796-807, 2008.

[50] M. V. Arena, O. Younossi, L. A. Galway, B. Fox, J. C. Graser, J. M. Sollinger, F. Wu, and C. Wong, Impossible Certainty Cost Risk Analysis for Air Force Systems. Santa Monica, CA: RAND Corp., 2006.

[51] D. J. O. Ferry and R. Flanagan, "Life cycle costing —A radical approach," CIRIA, London, U.K., Rep. 122, 1991.

[52] National Audit Office (NAO), "Through life management," NAO, London, U.K., Rep. HC 698, May 2003. Available: http://www. nao.org.uk/publications/0203/ministry_of_defence_through_l.aspx

[53] Australian National Audit Office (ANAO), Life-Cycle Costing in the Department of Defence, Canberra, A.C.T., Australia: ANAO, 1998.

[54] W. J. Fabrycky and B. S. Blanchard, Life-Cycle Cost and Economic Analysis. Englewood Cliffs, NJ: Prentice-Hall, 1991.

[55] R. J. Kirkham, M. Alisa, A. P. da Silva, T. Grindley, and J. Brøndsted, "EUROLIFEFORM: An integrated probabilistic whole life cycle cost and performance model for buildings and civil infrastructure," presented at the Int. Constr. Res. Conf. R. Inst. Chartered Surveyors, Leeds, U.K., 2004.

[56] North Atlantic Treaty Organization (NATO), "Methods and models for life cycle costing," NATO Res. Tech. Org., Tech. Rep. TR-SAS-054, Jun. 2007. Available: http://ftp.rta.nato.int/public// PubFullText/RTO/TR/RTO-TR-SAS-054///\$TR-SAS-054-TOC.pdf

[57] U.S. Government Accountability Office (GAO), Cost Assessment Guide Best Practices for Estimating and Managing Program Costs, Washington, DC: GAO, 2007.

[58] R. Crossland, J. S. Williams, and C. McMahon, "An object-oriented modeling framework for representing uncertainty in early variant design," Res. Eng. Des., vol. 14, no. 3, pp. 173-183, 2003.

[59] Treasury, The Green Book Appraisal and Evaluation in Central Government. London, U.K.: Stationery Off., 2003.

[60] N. Yoner, "Major weapon systems acquisition and life cycle cost estimation: A case study," M.S. thesis, Naval Postgraduate School, Monterey, CA, 2001.

[61] S. A. Book, "Why correlation matters in cost estimating," presented at the 32nd Annu. DOD Cost Anal. Symp., Williamsburg, VA, 1999.

[62] S. Cavalieri, P. Maccarrone, and R. Pinto, "Parametric vs. neural network models for the estimation of production costs: A case study in the automotive industry," Int. J. Prod. Econ., vol. 91, no. 2, pp. 165-177, 2004.

[63] A. Niazi, J. S. Dai, S. Balabani, and L. Seneviratne, "Product cost estimation: Technique classification and methodology review," J. Manuf. Sci. Eng., vol. 128, no. 2, pp. 563-575, 2006.

[64] T. Farineau, B. Rabenasolo, J. M. Castelain, Y. Meyer, and P. Duverlie, "Use of parametric models in an economic evaluation step during the design phase," Int. J. Adv. Manuf. Tech., vol. 17, no. 2, pp. 79-86, 2001.

[65] D. Ben-Arieh and L. Qian, "Activity-based cost management for design and development stage," Int. J. Prod. Econ., vol. 83, no. 2, pp. 169-183, 2003.

[66] R. Roy, Cost Engineering: Why, What and How? Cranfield, U.K.: Cranfield Univ., 2003.

[67] X. Chen, J. Yang, B. Li, and X.-A. Fen, "Methodology and technology of design for cost (DFC)," in Proc. 5th World Congr. Intell. Autom., Hangzhou, China, 2004, pp. 2834-2840.

[68] L. A. Galway, Subjective Probability Distribution Elicitation in Cost Risk Analysis: A Review. Santa Monica, CA: RAND Corp., 2007.

[69] R. Valerdi and R. J. Kohl, "An approach to technology risk management," presented at the Eng. Syst. Div. Symp., Cambridge, MA, 2004.

[70] T. Farineau, B. Rabenasolo, J. M. Castelain, Y. Meyer, and P. Duverlie, "Use of parametric models in an economic evaluation step during the design phase," Int. J. Adv. Manuf. Tech., vol. 17, no. 2, pp. 79-86, 2001.

[71] T. Farineau, B. Rabensalo, and J. M. Castelain, "Choice of costestimation functions based on statistical quality criteria and technical coherence," Int. J. Adv. Manuf. Tech., vol. 19, no. 7, pp. 544-550, 2002.

[72] Parametric Cost Estimating Handbook, Nat. Aeronaut. Space Admin., Washington, DC, 1995. 
[73] A. R. Mileham, G. C. Currie, A. W. Miles, and D. T. Bradford, "A parametric approach to cost estimating at the conceptual stage of design," J. Eng. Des., vol. 4, no. 2, pp. 117-125, 1993.

[74] S. Castagne, R. Curran, A. Rothwell, M. Price, E. Benard, and S. Raghunathan, "A generic tool for cost estimating in aircraft design," Res. Eng. Des., vol. 18, no. 4, pp. 149-162, 2008.

[75] S. A. Book, "Estimating probable system cost," in Crosslink, vol. 2, Systems Engineering. $\quad$ Los Angeles, CA: Aerosp. Corp., 2001. Available: http://www.aero.org/publications/crosslink/winter2001/02.html

[76] Department of Defense, "Affordability and lifecycle resource estimates," in Defense Acquisition Guidebook, Fort Belvoir, VA: Def. Acquisition Univ. Press, 2004, ch. 3.

[77] R. G. Chougule and B. Ravi, "Casting cost estimation in an integrated product and process design environment," Int. J. Comput. Integr. Manuf., vol. 19, no. 7, pp. 676-688, 2006.

[78] R. Miller and D. Lessard, "Understanding and managing risks in large engineering projects," Int. J. Proj. Manage., vol. 19, no. 8, pp. 437-443, 2001

[79] DE\&S, "A weapon system comes of age," in Desider, Bristol, U.K. DE\&S, 2008, pp. 16-17.

[80] P. Singh and P. Sandborn, "Obsolescence driven design refresh planning for sustainment-dominated systems," Eng. Econ., vol. 51, no. 2, pp. 115139,2006

[81] NASA Cost Estimating Handbook, NASA Cost Anal. Div., Washington, DC, 2008.

[82] A. O'Hagan, "Eliciting expert beliefs in substantial practical applications," Statistician, vol. 47, no. 1, pp. 21-35, 1998.

[83] M. Kishk, "Combining various facets of uncertainty in whole-life cost modelling," Constr. Manage. Econ., vol. 22, no. 4, pp. 429-435, 2004.

[84] L. A. Zadeh, "Fuzzy sets as a basis for a theory of possibility," Fuzzy Sets Syst., vol. 1, pp. 3-28, 1978.

[85] D. Dubois, L. Foulloy, G. Mauris, and H. Prade, "Probability-possibility transformations, triangular fuzzy sets, and probabilistic inequalities," Rel. Comput., vol. 10, pp. 273-297, 2004.

[86] E. Raufaste, R. da Silva Neves, and C. Mariné, "Testing the descriptive validity of possibility theory in human judgments of uncertainty," Artif. Intell., vol. 148, no. 1/2, pp. 197-218, 2003.

[87] R. E. Moore, Interval Analysis. Englewood Cliffs, NJ: Prentice-Hall, 1966

[88] M. Bruns, C. J. J. Paredis, and S. Ferson, "Computational methods for decision making based on imprecise information," presented at the NFS Workshop Rel. Eng. Comput., Savannah, GA, 2006.

[89] J.-G. Kang and D. Brissaud, "A product lifecycle costing system with imprecise end-of-life data," in Proc. 14th CIRP Conf. LCE, 2007, pp. 467472.

[90] E. K. Antonsson and K. N. Otto, "Imprecision in engineering design," J. Mech. Des., vol. 117, pp. 25-32, 1995.

[91] A. O'Hagan and J. E. Oakley, "Probability is perfect, but we can't elicit it perfectly," Rel. Eng. Syst. Saf., vol. 85, no. 1-3, pp. 239-248, 2004.

[92] W. Oberkampf, J. Helton, and K. Sentz, "Mathematical representation of uncertainty," presented at the AIAA/ASME/ASCE/AHS/ASC SSDM Conf. Exhib., Seattle, WA, 2001.

[93] S. Ferson and L. R. Ginzburg, "Different methods are needed to propagate ignorance and variability," Rel. Eng. Syst. Saf., vol. 54, no. 2/3, pp. 133 144, 1996.

[94] P. Walley, Statistical Reasoning With Imprecise Probabilities. London, U.K.: Chapman and Hall, 1991.

[95] S. Ferson and J. G. Hajagos, "Arithmetic with uncertain numbers: Rigorous and (often) best possible answers," Rel. Eng. Syst. Saf., vol. 85, no. 1-3, pp. 135-152, Sep. 2004.

[96] W. T. Tucker and S. Ferson, Probability Bounds Analysis in Environmental Risk Assessments. New York: Applied Biomathematics, 2003, pp. 1-63.

[97] J. M. Aughenbaugh and C. J. J. Paredis, "The value of using imprecise probabilities in engineering design," J. Mech. Des., vol. 128, no. 4, pp. 969-979, 2006.

[98] T. P. Anderson and J. S. Cherwonik, "Cost estimating risk and cost estimating uncertainty guidelines," Acquisition Rev. Q., vol. 4, no. 3, pp. 339-348, 1997.

[99] R. J. Malak, Jr., J. M. Aughenbaugh, and C. J. J. Paredis, "Multi-attribute utility analysis in set-based conceptual design," Comput.-Aided Des., vol. 41, no. 3, pp. 214-227, 2009.

[100] B. S. Blanchard and W. J. Fabrycky, Systems Engineering and Analysis, 2nd ed. Englewood Cliffs, NJ: Prentice-Hall, 1990.
[101] Y. Ben-Haim, Information Gap Decision Theory. London, U.K.: Academic, 2001.

[102] J.-Y. Jaffray and M. Jeleva, "Information processing under imprecise risk with the Hurwicz criterion," presented at the 5th Int. Symp. Imprecise Probability: Theories Appl., Prague, Czech Republic, 2007.

[103] S. Ferson and W. T. Tucker, "Probability boxes as info-gap models," in Proc. NAFIPS, 2008, pp. 1-6.

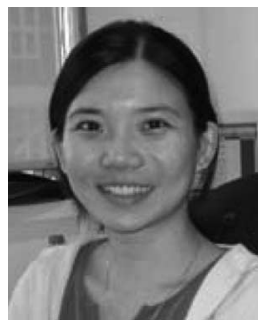

Yee Mey Goh received the Ph.D. degree from the University of Bristol, Bristol, U.K.

Her work was funded by the Overseas Research Students Award Scheme and the University of Bristol Postgraduate Scholarships. She is currently a Postdoctoral Researcher in the Innovative Design and Manufacturing Research Centre, University of Bath, Bath, U.K. She has been engaged in techniques for managing uncertainty in engineering design and simulation to mitigate risks and error in product development. Her current research interests include uncertainty in engineering design, decision theory, information management, service reliability, life cycle costing, and risk management. She has authored or coauthored several papers published in high-quality academic journals

Dr. Goh has been a member of scientific committees for a number of international conferences.

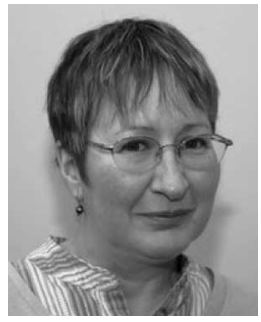

Linda B. Newnes received the Ph.D. degree from Loughborough University, Loughborough, U.K

She is currently with the University of Bath, Bath, U.K., where she leads the cost modeling research and manages a team of researchers engaged in numerous projects centered on through-life-cost modeling. Her research interests include cost modeling across all stages of the life cycle of the product, namely, concept-design, development, demonstration, manufacture, in-service, and disposal/recycle. She is also engaged in knowledge management approaches and utilizes the vast array of knowledge and information gathered throughout the life of the product.

Dr. Newnes is a member of the Managing Costs Through Life Steering Group, U.K. Ministry of Defence.

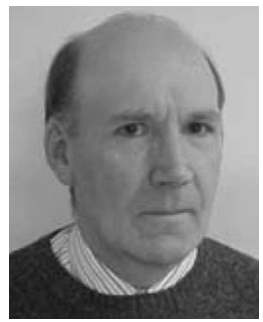

Antony R. Mileham received the Ph.D. degree from Coventry University, Coventry, U.K.

$\mathrm{He}$ is a Professor of manufacture in the Department of Mechanical Engineering, Innovative Design and Manufacturing Research Centre, University of Bath, Bath, U.K., and undertakes research in the areas of manufacturing processes modeling, Computer Aided Process Planning, cost prediction, flexible assembly systems, manufacturing system simulation, and rapid changeovers. He is also an Erskine Fellow at the University of Canterbury, Christchurch, New Zealand. He has authored or coauthored one book and more than 170 papers published in journals and presented at international conferences. He is an Editor of the Institution of Mechanical Engineers (IMechE) Journal of Short Communications in Design and Manufacture and a Book Review Editor of the IMechE Journal of Engineering Manufacture. He is the recipient of a Ford Motor Company Ltd. fellowship in 1991. 


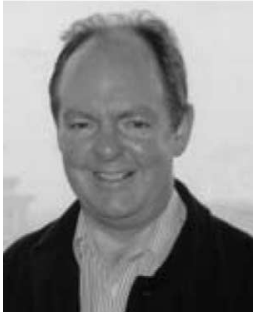

Chris A. McMahon is a Professor of engineering design in the Department of Mechanical Engineering, University of Bath, Bath, U.K., where he is also the Director of the Innovative Design and Manufacturing Research Centre. His current research interests include engineering design, especially the information needs of designers, the development of tools for information and knowledge management, design automation, risk and uncertainty management, and design for remanufacturing. He is an Associate Editor of the American Society of Mechanical Engineers (ASME) Journal of Computing and Information Science in Engineering. He is also a member of the editorial board of Research in Engineering Design, Journal of Engineering Design, and the Institution of Mechanical Engineers (IMechE), Part L Journal of Materials and Design. He is a Regional Editor of the Journal of Design Research. He has authored or coauthored more than 170 refereed papers, a number of edited volumes, and a textbook on computer-aided design and manufacture.

Prof. McMahon is the Deputy President of the Design Society. He has also been a member of the organizing panels and scientific committees of numerous conferences.

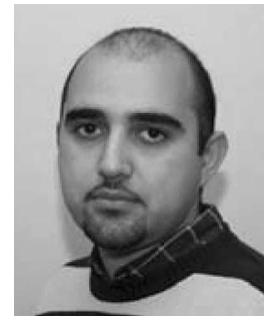

Mohammad E. Saravi is currently working toward the Ph.D. degree at the University of Bath, Bath, U.K., on estimating cost and improving tradeoff between performance and cost at the conceptual stage of design.

His work is funded by the Engineering and Physical Sciences Research Council. His current research interests include life cycle costing, product design and development, and design for manufacturing. 